\title{
EL PENSAMIENTO POLÍTICO Y SOCIAL DE LA ÉLITE AZUCARERA DEL NOROESTE ARGENTINO, 1910-1930
}

POR

\author{
María Silvia Fleitas
}

Unidad de Investigación en Historia Regional, Universidad de Jujuy

Al finalizar el siglo diecinueve se desarrolló un fenómeno interesante en la historia de las ideas en Argentina, centrado en la definición de la «identidad nacional» y motivado, en parte, por la continua llegada de inmigrantes y el aumento de las tensiones sociales. Este estudio analiza los factores sociales y económicos que influyeron en las posiciones adoptadas por la élite azucarera del noroeste argentino frente a la "cuestión social».

\section{INTRODUCCIÓN}

La Argentina finisecular y aún la del Centenario es indudablemente un país de cambios porque los nuevos factores resultantes de la integración a la economía mundial actuaron sobre su estructura socioeconómica produciendo transformaciones importantes, en muchos sentidos, desestabilizantes.

El conflicto social encuentra tierra fértil donde germinar: la estructura latifundista del campo argentino y los talleres y fábricas repletos de obreros, en gran mayoría inmigrantes.

Arrendatarios santafesinos protagonizan en 1912 el Grito de 
Alcortal (1). Durante los años 1918 y 1919, los peones rurales se suman a las huelgas agrarias que en 1921 enlutan el sur argentino con los sucesos de la "Patagonia Trágica» (2)... Son muestras del clamor del campo criollo e inmigrante, mientras que en las grandes ciudades del Litoral también los obreros bregan a través de sus organizaciones sindicales, por salarios más justos, sanción de leyes laborales, disminución del costo de vida y condiciones de existencia más dignas... Un reguero de huelgas que hace explosión en enero de 1919, durante la "Semana Trágica» (3), al calor de la prédica de anarquistas y socialistas.

Por esos años, el fin de la expansión de la frontera agrícola, el estallido de la Primera Guerra Mundial y la crisis posbélica, el cambio político derivado de la llegada al poder de Hipólito Yrigoyen (4), más una baja -desde 1926- de precios de los cereales a nivel internacional, enmarcan conflictivamente una etapa que la crisis de 1930 cerrará drásticamente.

En el plano de las ideas, y en el marco de lo que José Luis Romero denomina "el espíritu del Centenario», intelectuales y políticos centran su reflexión en la cuestión del «ser nacional». La problemática del inmigrante y el conflicto social, el creciente materialismo y cosmopolitismo de un nuevo estilo de vida que consume valores tradicionales, preocupa a la Argentina del Centenario, que sin renegar de la obra de la Generación del 80, entiende la necesidad de "rectificar su impulso y su rumbo, para preservar los valores morales y la tradición espiritual del país» (5). Se inicia en la Argentina el movimiento nacionalista con Gálvez y Rojas, precedidos por Lugones y la Generación del 1900, para quienes «era el aluvión de extranjeros, ávidos de

(1) Aníbal ARCondo: «El conflicto agrario argentino dé 1912. Ensayo de interpretación", en Desarrollo Económico, vol. 29, n.॰ 79, Buenos Aires, octubre-diciembre 1980. Waldo ANSALDI: "Revueltas agrarias pampeanas», en La vida de nuestro pueblo, n. 26, CEAL, Buenos Aires, 1982. 1954.

(2) Félix Luna: Yrigoyen, el templario de la libertad, Buenos Aires, Raigal,

(3) Edgardo Bilsky: La Semana Trágica, Buenos Aires, CEAL, Biblioteca Política Argentina, n.॰ 50, 1984.

(4) Martha H. CAvilliotti: "Yrigoyen. La causa contra el régimen en la Argentina", en Historia de América en el siglo $X X, n .^{\circ} 6$, Buenos Aires, CEAĹ, 1984.

(5) C. Paya y E. Cardenas: El primer nacionalismo argentino, Buenos Aires, Peña Lillo Editor, 1978, pág. 19.

R. I., 1996, n.o 206 
dinero y faltos de raíces en el país, el que había transformado esta reposada nación en una agitada factoría» (6)

En è noroeste argentino, el desarrollo de la industria más importante tampoco está exento de crisis y conflictos sociales. Como la condición de vida de sus trabajadores resulta de la explotación y la discriminación racial y social a que son sometidos, en las provincias azucareras también se protagonizan jornadas de lucha y de protesta reivindicativa. Aunque, "la duración y la organización laboral de las jornadas de trabajo sólo adquirían magnitud de cuestión social para las autoridades gubernamentales en la década del 20» (7).

El panorama social se complica todavía más porque la actividad azucarera cuenta con crisis propias; derivadas de los momentos de baja o exceso de la producción; en estas coyunturas entran en ebullición los intereses y necesidades particulares de los diferentes factores sociales involucrados y quedan al descubierto los conflictos que generan sus aspectos distributivos.

Los industriales azucareros se resisten a aceptar el rol del Estado como regulador de las relaciones sociales cuando quiere encauzar pacíficamente los reclamos populares mediante medidas de control social destinadas a disciplinar e integrar el movimiento obrero al sistema. Ante el conflicto social, el sector industrial asume una rígida postura patronal, negándose a aceptar una legislación laboral que significa derivar una parte de sus ganancias hacia mejores salarios, seguridad y condiciones de existencia más dignas para el trabajador del azúcar.

¿Cuáles son las razones que sustentan este comportamiento empresario, en primer lugar las que el sector arguye directamente, las desprendidas de su concepción de sujetos y clases sociales involucrados en esas instancias históricas, y aquéllas basadas en la realidad socioeconómica y política que pretenden dominar y que fundan, justamente, tales actitudes teóricas y políticas?

(6) Ibidem, pág. 15.

(7) Daniel SANTAMARÍA: Las huelgas azucareras de Tucumán, 1923, Buenos Aires, CEAL, Historia Testimental Argentina, n.o 26, 1984, pág. 14. 


\section{LA ÉLITE INDUSTRIAL Y LAS LEYES OBRERAS}

La política social del Estado argentino va tomando distintas direcciones según se complican las relaciones socioeconómicas en el seno de la sociedad urbana finisecular. Cambios en la estructura productiva y actores sociales recién incorporados se conjugan conflictivamente en una sociedad que intenta moverse dentro de nuevos parámetros capitalistas.

Juan Suriano explica cómo el Estado interviene en primera instancia desarrollando una enérgica actitud represiva ante hechos que considera de naturaleza policial: las huelgas y protestas son alteraciones del orden público provocadas por elementos disolventes. Pero cuando la gravedad de los hechos implícitos en la llamada "cuestión social» demuestra que no pueden resolverse sólo por medios coercitivos, sobreviene un cambio de estrategia. Es entonces que "comenzaron a desarrollarse políticas sociales impulsadas por el sector más reformador de la clase dominante con el objeto de establecer el control social sobre los sectores populares e intentar obtener un consenso que por las vías de la coerción no era factible alcanzar» (8)

En la primera década del siglo $\mathrm{xx}$ se aprueban las primeras leyes laborales sobre descanso dominical y trabajo de las mujeres y niños y se crea el Departamento Nacional del Trabajo, mientras en los años 20 se sancionan otras leyes tan importantes como el pago de salario en moneda nacional y la aplicación de las leyes de trabajo, como clara evidencia de numerosas infracciones.

La era radical hace su aporte al reformismo social en marcha, consustanciado con la prédica democrática, carente, sin embargo, de un cuestionamiento a tono de las bases del sistema económico vigente.

Los grandes intereses azucareros se oponen a la política radical, cuyas derivaciones sociopolíticas le quitan el manejo monopólico del poder. En efecto, el radicalismo viene a horadar la implantación electoral de los partidos conservadores en

(8) Juan SURIANO: «El Estado argentino frente a los trabajadores urbanos: política social y represión. 1889-1916", en Anuario, 14, Rosario, UNR Editora, 1989-1990, pág. 110.

R. I., 1996, n. ${ }^{\circ} 206$ 
las propias provincias norteñas y a modificar el sistema clientelístico sobre el cual se construye una parte esencial del modelo político vigente. Mientras que la orientación librecambista de la política económica desestima las pretensiones proteccionistas del sector industrial, el azúcar soporta, además de una legislación adversa erigida como defensora de los derechos del consumidor, la acción hostil de una prensa capitalista opositora. Por eso el discurso azucarero va a erigir sus argumentos contra la mejora social de los trabajadores, tanto frente a las leyes obreras como a las de confiscación o libre importación del azúcar, en cuanto a productos de una misma política «demagógica» (9).

En el Noroeste, la aplicación al sector azucarero de las leyes sociales por las cuales el Estado encauzara pacíficamente los reclamos obreros, es resistida con encono por los industriales arguyendo dos causas principales: que se coloca a la industria en inferioridad de condiciones respecto de sus pares extranjeras y que esas leyes están viciadas de inconstitucionalidad.

La resistencia industrial a la promulgación de las leyes 1348 y 1346 de salario mínimo y jornada de ocho horas por el gobernador radical Octaviano Vera, provoca la huelga obrera de 1923; ésta va tornándose cada vez más violenta ante la prescindencia del gobernador -que por decreto proclama la neutralidad del Ejecutivo sobre su aplicación- y la intransigencia patronal. Luego de la declaración de lock-out por los industriales y la intervención del ejército, la huelga es sofocada, aunque obtiene como victoria la legalización de las leyes recientemente sancionadas.

Ante la sanción del Ejecutivo Provincial de las leyes de jornada legal de ocho horas y de salario mínimo, la Revista Azucarera -órgano oficial del Centro Azucarero Nacional- traduce la posición del sector industrial, expresando: «[...] Las

(9) Los representantes parlamentarios conservadores de la élite azucarera aluden al carácter "demagógico» de tales acciones para invalidar los ataques a la industria. «(...) todos los entusiasmos, todos los halagos de los políticos, todas las medidas legislativas tienden a cortejar al consumidor urbano, leguleyo y votante por más que ellas esquilmen al productor rural», dice Marcos Rougs (uno de los propietarios del ingenio "Santa Rosa") en un escrito contra la Ley Confiscatoria del azúcar del año 1920. En Revista Azucarera, Año XVIII, n.o 212, Bs As, agosto de 1920, pág. 280. 
dos leyes colocan a la industria azucarera argentina en condiciones de inferioridad con respecto a la de otros países, especialmente aquellos que emplean mano de obra de hombres de color, entre ellos países productores tan importantes como Cuba, Java, Hawaii; el Brasil y las Antillas Británicas, inclusive la Guayana. Colocan, por otra parte a Tucumán en condiciones desfavorables en comparación con otras regiones azucareras del país» (10).

Para el jujeo Benjamín Villafae (11), vocero político de la élite azucarera regional, la "supuesta» defensa del trabajador argentino que estas leyes se proponen en un artilugio de los demagogos para captar la adhesión popular, puesto que los altos salarios sin una protección arancelaria a las industrias nativas que las defienda de la competencia extranjera, obra tanto en perjuicio del obrero como del industrial. Se pregunta Villafae:

¿Cómo puede el productor argentino, el que elabora azúcar, como el que siembra arroz o cultiva yerba mate, ofrecer sus productos al pueblo, al mismo precio que el industrial de Brasil o el Paraguay, donde se paga al hombre de color un salario que equivale a setenta centavos de nuestra moneda, sin la obligación de darle casa ni asistencia social? Para que las industrias del país puedan vivir con los altos salarios y gravámenes impuestos al capital por los socialistas y demás partidos que se disputan el voto del obrero, es menester que se defienda estos salarios con una barrera de aduana que ponga condiciones con el extranjero" (12).

Se sostiene, en fin, que del factor "mano de obra barata» depende el desarrollo exitoso de la industria azucarera nativa y su competitividad; sin embargo, es un hecho que el valor otorgado al mantenimiento de la fuerza de trabajo asalariada en el cálculo de los costos totales de producción está sobredimensionado y responde sólo a la intención del sector indus-

(10) Citado en Daniel SAnTAmaría: Las huelgas azucareras de Tucumán, 1923, op. cit., págs. 19-20.

(11) Benjamín Villafae (1877-1952). Diputado Provincial (1909-1910), (19171918); Diputado Nacional (1920-1924); Gobernador de Jujuy (1924-1927); Senador Nacional (1932-1941).

(12) Benjamín VillafaE: "En defensa de la vida económica del Norte». En La Industria Azucarera, Año XXXVI, n. 445 , Bs As, noviembre de 1930, pág. 774.

R. I., 1996, n.o 206 
trial de conservar sus ventajas en la distribución de las ganancias finales.

Los industriales invocan además los derechos de libertad de trabajar y de contratar, consagrados en el artículo 14 de nuestra Carta Magna, para sostener que las leyes de limitación de jornada laboral y de salario mínimo las vulneran. No reparan en citar para esta ocasión a los «defensores del liberalismo económico y del individualismo de Constitución" aunque tradicionalmente, en defensa de sus intereses sectoriales, hayan apelado a principios doctrinarios opuestos. Con palabras de Alberdi, Sixto Terán (h.) afirma:

"Al derecho individual, al interés de cada uno corresponde, y no al poder del Estado, organizar y reglar las condiciones del trabajo, para que sus beneficios se compartan entre todos, con una igualdad que la ley no puede establecer sin violar el derecho de algunos otros» (13).

Así como se solicita la intervención del Estado en cuestiones de política económica para «salvaguardar la riqueza nacional», se rechaza su participación como regulador de las relaciones sociales. Además de ilegítimo se considera arbitrario, pues, que el Estado intente reemplazar la libertad contractual entre patrones y obreros con leyes rígidas y ficticias, en una política de halago a las masas electoras (14).

Postura que se condice con la de defensa patronal asumida ya desde los albores del siglo por la entidad nacional representativa de los sectores empresariales, la Unión Industrial Argentina. Para esta asociación «la intervención mesurada del Estado es sin duda alguna, legítima, conveniente y provechosa (en cuestiones fundamentales de justicia, higiene y seguridad); pero cuando forzado el concepto, como lo han hecho los autores del proyecto de la ley nacional del trabajo -expresa en una

(13) «El salario mínimo. Exposición del Centro Azucarero Nacional. Institucionalización de la Ley Fallo de la Suprema Corte de Estados Unidos», Buenos Aires, Ferrari Hnos., 1923, pág. 23.

(14) «(...) por razones de política electoral, se han sancionado leyes rígidas que fijan cuál ha de ser el salario mínimo del trabajador. Esas leyes no contemplan, pues, una necesidad social. Por ello y porque sus autores no han tenido otro propósito que halagar al electorado, son arbitrarias». İdem, pág. 11. 
nota a la Cámara de Diputados en 1905- se extrema esa intervención hasta hacerla tiránica, o se la emplea en cuestiones secundarias, o que por su naturaleza escapan a su dominio -como sucede en gran parte con la libertad de contratos-, acontece fatalmente que se convierte en un mal social cien veces peor que los que se quieren atenuar o remediar con ella». Incluido el grave trastorno para la producción nacional que el abandono del régimen de libertad de trabajo acarreara, ya que "nuestras industrias quedaran colocadas en notable inferioridad respecto a las industrias similares extranjeras, con las que no podría ya competir puesto que cada una de esas restricciones implica directa o indirectamente, un aumento en el costo de la producción» (15).

Con estas actitudes la UIA, se constituía en un «obstinado frente de oposición -y resistencia- a toda tentativa de mejoramiento legal en las condiciones de vida y trabajo de los trabajadores", afirma Cíneo, creyendo que "no habrá manera (...) de basar nuestra industria que sobre la jornada de 10 y 12 horas de labor, sin descanso dominical pago, en trabajo de niños y mujeres hasta en jornadas nocturnas, sin Código de Trabajo (...)» (16).

De idéntica manera, los industriales azucareros fortalecen sus lazos internos y se disponen a defender los valiosos intereses particulares en juego cuando madura el tiempo de la lucha obrera. Expresa Alfredo Guzmán en 1923 -año de las violentas huelgas azucareras en Tucumán-, en ocasión de asumir la presidencia del Centro Azucarero Regional, filial del reorganizado Centro Azucarero Nacional en la Capital Federal: "Nuestro deber del momento, ya que nos sentimos fuertes con la solidaridad y la unión, es mantener el compromiso de honor que hemos contraído para evitar no sólo estos atropellos inauditos a nuestros propios intereses, sino también por la tranquilidad de esta rica provincia, que por sus méritos conquistados desde la época de nuestra historia nacional, tiene derechos adquiridos para exigir de sus hijos que reaccionen del letargo en que estén sumidos, ejerzan los derechos que les acuerda la Consti-

(15) Citado en Dardo CunEo: Comportamiento y crisis de la clase empresaria, 1, Buenos Aires, CEAL, Biblioteca Política Argentina, n. 68, 1984, pág. 66.

(16) Ídem., pág. 68.

R. I., 1996, n.० 206 
tución, mirando con patriotismo y desinterés el engrandecimiento y el bienestar general de la misma y se den gobiernos que merecen, es decir, de respeto y de progreso" (17).

Se insiste, en fin, en que las clases populares no tienen conciencia del bien que les ofrece esa «mano blanda y protectora»-en palabras del tucumano Ernesto Padilla- con leyes que alteran su arraigada costumbre de "servir y temer» (justo salario, pago en moneda nacional, jornada de ocho horas de labor, etc.): «Para aceptar la bondad es necesario poder comprenderla» -sentencia el político azucarero hacia el año 1908-. De allí que los beneficios sociales ofrecidos produjeran efectos contrarios a los deseados; la clase obrera tiende con ellos al «menor trabajo y a la mayor holganza» (18).

En definitiva, un viejo alegato "paternalista» que invocando conocer la «idiosincracia del peón» aconseja, por ello, el trabajo intenso y continuo si realmente se quiere su beneficio.

En la década del 20, los empresarios azucareros rechazan el reformismo social manteniendo los mismos argumentos citados por Padilla quince años atrás: estas leyes «lejos de favorecer al obrero de una manera inmediata (...) lo perjudicará grandemente al relajar la disciplina y favorecer la tendencia del mismo al vicio y a la holganza (...)» (19).

Estas posiciones retrógradas en materia social responden a una mentalidad formada en un clima intelectual en el que el movimiento positivista y el antiliberalismo nacionalista imponen su impronta. Analicemos, pues, la concepción de sociedad, élites y pueblos que éstas suponen.

\section{EL ORDEN SOCIAL EN EL PENSAMIENTO DE LA ÉLITE}

Casi todos los países de Latinoamérica experimentan en los últimos decenios del siglo xIX y principios del $\mathrm{xx}$ cambios

(17) Emilio ScHLEH: Los grandes pioneers de la Argentina. La obra econónulca y social de don Alfredo Guzmán, Buenos Aires, Guillermo Krafts Ltda., 1943, pág. 132.

(18) Ernesto Padilla: Discurso de Clausura del Congreso Católico en Tucumán, 1908, Archivo Padilla, Carpeta 21, Archivo Histórico de Tucumán.

(19) Revista Azucarera, Año XX, n.o 233, Buenos Aires, mayo de 1922, págs. 130 a 132 .

R. I., 1996, n.o 206 
socioeconómicos que, promovidos por los grupos liberales ilustrados, provocan, sin embargo, una reacción negativa de éstos frente a una acentuación de la movilidad social y ascenso político de grupos subalternos a que aquéllos dan lugar. $\mathrm{Fe}$ nómeno que, según lo explica José Luis Romero, abre paso a una doble corriente del pensamiento: «Por una parte comenzó a desarrollarse una fuerte tendencia a los estudios sociológicos, inspirada generalmente en Comte y en Spencer, cuyo objetivo era buscar las razones profundas del estado de inquietud social que caracterizaba la vida latinoamericana; y por otra comenzó a fortificarse una corriente de pensamiento político que justificaba el papel de las aristocracias y la función de los gobiernos fuertes» (20).

En nuestro país, el sociologismo orienta muchas preocupaciones intelectuales del Centenario, en el marco de lo que Alejandro Korn llama el "positivismo nacional», el cual encara especialmente el tópico del carácter o la indosincracia del pueblo argentino, tratando de desentrañar sus claves psicológicas y espirituales.

Agustín Álvarez, Alfredo Palacios, Carlos Octavio Bunge, Juan Agustín García, Joaquín V. González, Juan B. Justo son algunos exponentes de esta corriente ideológica, los cuales se deleitan en leer a autores extranjeros -además de Comte y Spencer- como Taine, Darwin, Fouille, Fustel de Coulanges, Stuart Mill, Le Bon u otros. "Este último fue uno de los socioorganicistas franceses que mayor resonancia obtuvo en el pensamiento americano finisecular; especialmente con los estudios sobre el alma de las masas en tanto producto técnico y ambiental, con las reflexiones en torno a que cada pueblo posee una organización mental -tan fija como la anatómica-, desde la cual emanan sus sentimientos, ideas, arte e instituciones» (21).

El credo positivista de estudiar a la sociedad como se estudiaba a la naturaleza, concebirla entonces como un organismo,

(20) José Luis Romero: Situaciones e ideologías en Latinoamérica, Buenos Aires, Editorial Sudamericana, 1986, pág. 46.

(21) Hugo BiAgINI: «Acerca del carácter nacional». En Hugo Biagini (Compilador), El movimiento positivista argentino, Buenos Aires, Editorial de Belgrano, 1985, págs. 26-27.

R. I., 1996, n.o 206 
y el evolucionismo social spenceriano, con su aplicación de la ley de la evolucióm darwinista a la sociedad, inspiran los análisis de la realidad argentina.

Así como en Europa, la sociología había nacido como «una ideología del orden, del equilibrio (...) íntimamente ligada con los objetivos de estabilidad social de las clases dominantes» (22), aquí, los estudios sociológicos se multiplican cuando la inquietud social de albores del siglo siembra incertidumbre en la clase política gobernante. La idea que concibe el orden social como organismo regido por leyes similares a las de la naturaleza, que mantienen las jerarquías y establecen las funciones de sus miembros permitiendo, así, la evolución de las sociedades a estadios superiores, se adecúa a los intereses de una oligarquía amenazada en su poder.

La respuesta a la pregunta de Hugo Biagini «ciqué función se le adjudica al pueblo, a las masas, en la plasmación del carácter nacional?» ilustra bien la participación asignada a las clases sociales en la construcción del devenir histórico. «Para algunos positivistas, los entes colectivos carecen de mayor relevancia como sujeto histórico -explica el autor-, estimándose que la civilización argentina fue gestada por una docta minoría y no por las multitudes incultas, cuya proscripción habría permitido el ejercicio de gobiernos idóneos. En esta visión, la muchedumbre, como un rebaño rutinario, carece casi de conciencia y de ideologías orgánicas, cayendo fácilmente en la intolerancia y el autoritarismo» (23).

El movimiento nacionalista retoma esta idea de pueblo, presente en el discurso contrarrevolucionario primigenio y es común -aún debido a distintas fundamentaciones- a conservadores católicos y adherentes a las nuevas corrientes como el darwinismo.

La vena tradicionalista se ocupa de destacar la influencia insana para la sociedad argentina del aluvión inmigratorio, una masa urbana que viciaba de «materialismo» y "cosmopolitismo» el alma nacional. Después del 14, y sobre todo a partir

(22) Juan Carlos Portantiero: La sociología clásica: Durkheim y Weber, Buenos Aires, CEAL, Biblioteca Total, n. 16, 1977, pág. 12.

(23) Hugo BiAgINI: [21], pág. 32. 
de los años 20, los nacionalistas -lecturas de Maurras (24) de por medio- avanzan en el campo político rechazando la participación popular en el gobierno. El desdén por los sectores populares deriva, en efecto, en una adversión a la democracia, al sufragio universal y secreto y a los dogmas igualitarios, representados en el yrigoyenismo (25). En efecto, junto a la xenofobia nacionalista se predica la ineptitud de la masa votante para decidir su destino comunitario; en todo caso "el pueblo tenía derecho a ser bien gobernado, pero no a gobernar», escribe David Rock explicando el pensamiento de Ernesto Palacio (26).

Ahora bien, es en este marco ideológico general que se inserta el pensamiento de la élite industrial azucarera -entre cuyos miembros, lógicamente, es posible establecer matices-. Marco en el que debemos incluir aún el discurso legitimador de la existencia de la industria del azúcar puesto que es a su servicio que se manejan los conceptos de orden y progreso social en cuestión.

(24) Charles Maurras (1868-1952), escritor y político francés, líder de "Action Française" y defensor de la resturación monárquica, para quien la Revolución Francesa es el hecho catastrófico más grande de la historia moderna, y el liberalismo la "primera bestia que se debe matar». Define la democracia como "un monstruoso régimen judeo-masón» o como «la dictadura del vulgo".

(25) Las manifestaciones despectivas hacia las clases populares de Benjamín Villafae constituyen claro ejemplo. Para el jujeo el proletariado urbano del litoral se le presenta como "turbas inconscientes», "masas sin cultura», fácil presa de la prédica demagógica de radicales y socialistas. En La Industria Azucarera, Año XXXI, n.o 386, Bs As, diciembre de 1925, pág. 1325. En 1928 escribe: "Pueblo! carne debilitada y enferma, que lleva en la pupila cansada, el reflejo de la miseria, de la inquietud y de la desesperanza al fin de la jornada fatigosa de cada día! eres la eterna víctima de los que amas como apóstoles auténticos, cuando en el fondo no son otra cosa que fariseos de la vida pública, lobos rapaces disfrazados de corderos! Imaginas que existe en este mundo un ser o millares de seres con un dogal anudado al cuello, con grilletes y cadena al pie, que besen las manos del ser que los escarnece y explota? Ese ser, esos millares de seres están a la vista de todos; os codeáis con ellos a cada instante: son esos desgraciados, débiles de espíritu, de inteligencia, sin cultivo que en el pueblo argentino se llaman irigoyenistas (...)" En Benjamín VILlafaE: Degenerados, Buenos Aires, 1928, págs. 175-176.

(26) David Rock: La Argentina autoritaria. Los nacionalistas, su historia y su influencia en la vida pública, Buenos Aires, Ariel, 1993, pág. 98. 
Este discurso presenta a la agroindustria como "un índice económico de la civilización del Interior», "movida por la iniciativa y la audacia de los criollos», por la cual "el trapiche logró crear y formar un núcleo sólido de irradiadora fuerza social, económica y política, allí, donde una necesidad la reclamaba» (27). El tesón de unos pocos "pioneers" implantó la industria que "ha cumplido» (...) un gran fin social educando, infundiendo hábitos de trabajo y moral, la gran masa de población inculta -escribe Pedro Alurralde (h.) en un informe a Estanislao Zeballos, Ministro de Relaciones Exteriores de la Nación- que, en nuestras campañas, era una amenaza constante contra la tranquilidad pública y un mentís a la cultura de nuestra sociedad" (28). Más o menos las mismas palabras y el mismo significado utiliza Emilio Schleh -historiador «oficial» de la industria azucarera- para señalar el aporte social de la actividad para despojar «de su aspecto primitivo» a la vida de la región. Motor de progreso que trajo aparejado la proletarización de una población mayormente rural, que en un principio se resistió al "primer paso de civilización industrial que marcaba el camino del porvenir» (29).

A pesar de este «alarde civilizador» en cuanto a la «misión social» emprendida por la industria, la clase trabajadora siempre mantiene para la élite un carácter primitivo e inmoral, susceptible de control por una clase superior. Un concepto

(27) Ernesto Padilla: "La industria azucarera y las provincias del Norte». Discurso pronunciado en la Inauguración del Pabellón de las Provincias de Tucumán, Salta y Jujuy en la Exposición Industrial del Centenario, 16 de octubre de 1910, Buenos Aires, 1910, págs. 4 y 5.

(28) Pedro Alurralde (h.): «La industria del azúcar. Un documento de sus tiempos difíciles», Buenos Aires, febrero 13 de 1890, pág. 177.

(29) «El paisanaje nómada y levantisco, que lo era por carecer de medios normales de subsistencia y no por instinto, abandonó su vida errabunda y de pillaje aprovechada tan largamente por los caudillos del interior y supo asociarse, en beneficio de todo el país, a las faenas industriales que le brindaban la quietud y el bienestar que les fuera desconocido antes. Esta sola conversión al trabajo, de gran parte de los habitantes de una vasta región del interior, que encontraba al fin el medio de aplacar su miseria, revela la trascendencia que para la vida social tuvo la creación de la industria" Emilio SCHLEH: «La industria azucarera en su primer centenario. Introducción de un libro en preparación". En Revista Azucarera, Año XIX, n. 223, Bs As, julio de 1921, págs. $479-480$. 
desmerecedor de las clases obreras, vertido por Ernesto Padilla resulta buen ejemplo para los dicho: «(...) se trata de una clase social ineducada -afirma en 1904-, sometida mucho tiempo a una condición inferior; (que) se ha creado en medios materiales propicios para todos los desenfrenos; (...) familiarizado con la iniquidad y (...) con el remoto recuerdo ancestral del encomendero (...)» (30).

Nada más errado que conceder prendas de confort y ocio a quienes las desperdiciaran... Al considerarse en la Cámara de Diputados un despacho de ley sobre el pago de salarios en dinero en efectivo, la representación de Jujuy y Tucumán se opone especialmente al artículo que prohíbe al patrón descontar de los sueldos montos en calidad de adelantos en especie o retener parte de ellos como pago de posibles deudas del obrero. «El obrero no tiene previsión -afirma en esa ocasión el diputado tucumano Len Rougs, y lo hace como patrón a cargo de empleados-; el obrero está acostumbrado a tener adelantos hasta de la carne con que alimenta a sus hijos, y esta disposición le impedirá obtener ese adelanto (...), en tal forma que se le va a colocar a ese hombre, sin condiciones para la economía ni para la previsión, frente a una ley que le quita todo recurso para alimentar a su familia» (31). Por su parte, la revista Azucarera al negarse a la jornada de ocho horas de labor, concede al elemento trabajador el mismo poco crédito aseverando:

«(...) nuestro peón no practica el ahorro, y en su gran mayoría sólo trabaja unos días más a la semana, pasando el resto en la mayor inactividad, pues el salario de unos días le es suficiente para toda la semana. No conoce tampoco los pasatiempos saludables y disminuir por ley las horas que trabaja es incitarlo a que caiga más bajo en el vicio, facilitándole la oportunidad» (32).

(30) Ernesto Padilla: "Discurso de Clausura del Congreso Católico en Tucumán», [18], pág. 5 .

(31) Diario de Sesiones de la Cámara de Diputados de la Nación, Año 1920, t. V, pág. 166.

(32) Revista Azucarera, Año XX, n.o 233, Bs As, mayo de 1922, pág 132.

(32) Marcelo LaGos: "Conformación del mercado laboral en la etapa de despegue de los ingenios azucareros jujeos (1880-1920)", en Daniel CAMPI, (Compilador), Estudios sobre la historia de la industria azucarera argentina, 
El universo indígena -que proporciona mediante coacción fuerza de trabajo a los indígenas de Salta y Jujuy- (33) se incorpora a esta concepción de la clase trabajadora dentro del «viejo esquema de oposición binaria 'civilización/barbarie' o 'naturaleza/cultura'» que funciona como mentalidad del vencedor con la conquista y colonización. Respecto al nativo de estas tierras se crean "clichés de larga duración (como la pereza y la soberbia) [que sirven] para exaltar la misión 'civilizadora' del blanco» (34), que se lleva a cabo a través de la difusión de la religión, la educación y el trabajo "productivo».

Aún para los que bregan por un trato más digno hacia ellos, les resulta imposible pensar en otros términos. Que el articulista del periódico jujeo «El Día», hacia 1915, haya elegido titular un artículo destinado a esos fines «El problema del salvaje» es un claro ejemplo (35). Meses antes ya había escrito:

"Consideramos que esa 'desgracia' de haber nacido indios no debe pesar sobre sus frentes cobrizas como un estigma hasta el punto de sacrificar los sentimientos de humanidad que nos debemos los hombres mutuamente» (36).

Los ingenios jujeos dependen en alto grado de estos trabajadores temporales, cuya captación excede el ámbito local por ser éste insuficiente, de allí que tribus de wiches, tobas, mocoves y vilelas de la región chaquea sean reclutados para la zafra. «Pero a pesar de la presión sobre sus fronteras, los indígenas no siempre estaban dispuestos a concurrir a un trabajo cuyo ritmo y frecuencia no formaba parte de sus pautas culturales. Por eso los ingenios enviaban año a año expediciones con mayordomos y personal de planta para tratar de tentar lenguaraces $\mathrm{y}$, regalos de por medio, a los caciques de las parcialida-

vol. II, Unidad de Investigación en Historia Regional (UNJu) y Ėdiciones del Gabinete-Secretaría de Postgrado (UNT), 1992. Daniel SANTAMARÍA «Migración laboral y conflicto interétnico. El caso de los migrantes temporarios en los ingenieros saltojujeos». En CAMPI, [32].

(34) Thierry SAIGNES: Ava y Kara. Ensayos sobre la frontera chiriguana (siglos XVI-XX), La Paz, Hisbol, 1990, pág. 210.

(35) El Día, Año VI, n. 1540, Jujuy, miércoles 22 de diciembre de 1915.

(36) El Día, Año VI, n.o 1435, Jujuy, viernes 13 de agosto de 1915. 
des. (...) Si la situación del obrero era en su conjunto de desamparo, la del aborígen chaqueo, que aún ofrecía resistencia al avance blanco, se presentaba en extremo complicada. A los que proponían, aunque siempre en forma velada, el exterminio de estos indios, secularmente indómitos y brutales según preconceptos que se forjaban desde tiempos coloniales; se oponían las opiniones de aquellos que arguían que el país debía incorporarlos a la civilización a través del trabajo. Entre la forma que pensaron ciertos hombres públicos y funcionarios debía producirse ese ingreso al mundo laboral, y el que les impuso la realidad de la poca y la avidez de las empresas de desarrollo, hubo un notable desfasaje» (37).

Sin embargo, en la versión oficial de los empresarios y políticos azucareros, la pacificación del indio y la consiguiente conversión a trabajador disciplinado es uno de los preciados objetivos alcanzados por el orden social que la industria ha inaugurado. Así lo deja establecido Vicente Padilla al presentar las razones que fundan el pedido de su protección:

«Hay, sobre todo, dos factores en la industria azucarera, que la nación debe tener presente para dispensarle su más franca y decidida protección y ellos son: 1 que el $95 \%$ del brazo que trabaja en esta industria, es argentino y que los aborígenes de esta tierra, en su inmensa mayoría se han civilizado, han aprendido a respetar la soberanía nacional y a comprender el concepto de patria, trabajando en esta industria, la que a cambio de su labor le ha proporcionado, en la generalidad de los casos, un indiscutible bienestar (...)» (38).

En verdad, esta versión tiene una gran cuota de deformación de la realidad, pues tras esta visión casi mítica de la industria azucarera, además de esconder situaciones en extremo contrapuestas, emerge un proceso de coacción y violencia dirigido a lograr la proletarización del indígena como mano de obra

(37) Marcelo Lagos: Estudio Preliminar de Investigación sobre los indios matacos trabajadores a cargo del Inspector Jos Elas-Niklinson, 1917, Jujuy, UNJu, 1989.

(38) Vicente Padilla: El Norte Argentino. Historia Política, administrativa, social, comercial e industrial de las provincias de Tucumán, Salta, Jujuy, Santiago del Estero y Catamarca, Buenos Aires, Ferrari Hnos., 1922, pág. 257. 
para la industria del azúcar; el mismo que para otras industrias nacionales en expansión, como el algodón o la madera. En efecto, según explica Nicolás Iñigo Carrera, la creación de condiciones para el dominio del capital industrial en la Argentina estuvo vinculada con las campañas militares al Chaco, la Pampa y la Patagonia.

Las campañas al Chaco de 1884 y 1911 tienen como claro objetivo convertir a los indígenas en obreros, proporcionar «brazos baratos» a la industria azucarera y a los obrajes de una amplia región. Hacia mediados de 1930 el proceso se ha completado, "un modo de producción había sido destruido, se había creado la condición primera para que el capital pusiera en producción ese territorio: la existencia de obreros 'libres', independientes y privados de sus condiciones materiales de existencia» (39). La "reducción» cumpliría, a su vez, con el rol complementario de «disciplinamiento» y entrenamiento de ese trabajador indígena...

Las empresas jujeas, necesitadas de mano de obra estacional -en connivencia con las autoridades militares del Chaco que auspician de intermediarias- colaboran en este proceso calculando los beneficios que de él obtienen (40).

Hacia mediados de 1910, constituido el contingente de población indígena proletarizada, Jujuy recluta sobre todo wiches y chiriguanos del oeste chaqueo mientras que tobas -del este y centro- se distribuyen entre los ingenios del Chaco. Con el fomento de la producción del algodón, el gobierno territorial prohíbe en 1924 la salida a la zafra de tales parcialidades, asegurándose así la mano de obra necesaria para la cosecha de ese cultivo industrial.

Se puede completar la visión de este orden social construido por la industria azucarera aludiendo a la condición social de esta población proletarizada; sujeto de explotación y discriminación racial y social, las necesidades de vivienda, educación, salud y salarios dignos del trabajador del azúcar no son

(39) Nicolás INIIGo CARRERA: La violencia como potencia económica: Chaco 1870-1940, Buenos Aires, CEAL, Conflictos y Procesos, n. 11, 1988, pág. 12.

(40) V. Conti, Ana T. DE Lagos y M. Lagos: Mano de obra indigena en los ingenieros de Jujuy a principios de siglo, Buenos Aires, CEAL, Conflictos y Procesos, n. ${ }^{\circ}$ 17, 1981, págs. 23-24. 
atendidas más que en rarísimas ocasiones. Los «beneficios» de «civilización» y "progreso» proclamados por la élite como aportes de la industria azucarera, quedan, entonces, cuestionados por la realidad irrefutable de la condición de vida de sus trabajadores. "Los obreros en el ingenio -escribe el diario tucumano "El Orden»- viven en un sombrío hacinamiento en habitaciones que son verdaderas pocilgas, construcciones antiguas y fétidas. En esas parodias de hogares, la falta de higiene es predominante: no tienen piso, como los corrales, y como su número es escaso, se hacinan en esos refugios como enjambres, carecen de baños, el agua que se bebe es poco menos que impotable, propia para producir enfermedades de toda naturaleza» (41). Mientras que los zafreros salteos tampoco gozan de una situación diferente, "hacinados en insalubres galpones, condenados a permanecer en chozas, desprotegidos de todo amparo legislativo" (42)... Los vales y la proveedura esquilman al obrero, dejándolo endeudado y con casi nada una vez terminada la zafra. La prensa jujea se hace eco de la situación -teniendo en cuenta que en Salta y Jujuy es habitual el pago de jornales en un $100 \%$ no monetario- y denuncia con frecuencia el hecho; así, «El Día» de 1915 publica la existencia de vales de distinto valor en el ingenio La Mendieta con los cuales éste abona a sus peones. El ingenio les exige que «los conviertan en mercaderías en los almacenes de la casa o un descuento del $20 \%$ para dárselos en dinero efectivo» (43). Aún cuando "se produjo una tendencia general a ir abandonando el pago en especie, vale, ficha y retención del salario, para hacer la liquidación en moneda nacional y en forma regular (...) -afirma Marcelo Lagos- éste constituye parte de un proceso muy lento que en la práctica se dio en forma híbrida, ya que en la década de 1930 encontramos al lado de la generalización de la relación monetaria, la permanencia del pago en fichas, la tarja y descuentos por libreta» (44).

(41) El Orden, Tucumán, 27 de enero de 1925.

(42) Gregorio CARO FIgUeroa: Historia de la gente decente en el Norte Argentino, Buenos Aires, Ediciones del Mar Dulce, 1970, pág. 232.

(43) El Día, Año VI, n.o 1371, Jujuy, sábado 22 de mayo de 1915.

(44) Marcelo LAGos: «Estructuración de los ingenios azucareros jujeos en el marco regional (1870-1940)». En Proyecto NOA, n.o 3, El Noroeste argentino 
En síntesis, las posturas y comportamiento de la élite azucarera frente a la llamada «cuestión social» responden, por un lado, a una concepción elitista de las relaciones sociales. Por otro, a la necesidad de preservar intactos sus intereses y privilegios en el orden social constituido a partir de la industria azucarera. Asimismo no constituyen una excepción de las asumidas por la generalidad del empresario argentino, mientras que el pensamiento que las acompaña se inscribe en las corrientes de ideas de la época.

Sin necesidad de atribuir su aceptación de la coacción y la violencia en las relaciones laborales -rastreables en la época del "despegue azucarero" tucumano, en la segunda mitad del siglo XIX- o su resistencia al reformismo social -atenuando entre sus miembros adherentes al catolicismo social- (45) a una «mentalidad tradicional» propia de «señores feudales» (46), se trata indudablemente de posturas retrógradas engarzadas perfectamente a un proyecto político elitista. Analizaremos a continuación algunas ideas que lo sustentan.

\section{ELITISMO SOCIAL E IDEAS POLÍtICAS}

Los años que enmarcan nuestro estudio guardan una etapa decisiva de la historia política argentina: el coronamiento de un proceso de reforma social con la sanción de la Ley del Voto Universal y Secreto; la caída del régimen conservador y la llegada al poder del radicalismo yrigoyenista.

La ampliación de los derechos políticos tiene una receptividad dispar entre los miembros de la élite regional. Respondiendo a distintas tendencias -según fueran católicos, nacionalistas,

como región histórica. Integración y desintegración regional. Estudio del país interior. Junta de Andalucía, 1993, pág. 163.

(45) Néstor Tomás AuZA: Aciertos y fracasos sociales del catolicismo argentino, Buenos Aires, Editorial Docencia, 1987. Héctor RECALDE: La Iglesia y la cuestión social (1874-1910), Buenos Aires, CEAL, Biblioteca Política Argentina, n. ${ }^{\circ} 110,1985$.

(46) Cfr. Daniel CAMPI: «La fuerza de trabajo en el 'despegue azucarero' tucumano. Mecanismos de contratación y condición social, 1875-1896». Ponencia presentada en las «Primeras Jornadas Inter-escuelas Departamentos de Historia», La Plata, octubre de 1988. 
liberales, positivistas o de alguna variación propia de todas ellas- aceptan o rechazan, parcial o totalmente, la Ley Electoral de 1912. Pero a pesar de los matices, no es mucha la distancia que los separa, pues nunca dejan de ser visiones elitistas; en ellas prima la idea de un orden donde los grupos sociales cumplen roles diferentes, para cuyo desempleo eficaz deben prepararse. Dentro de ellos, las funciones de gobierno corresponden a una élite ilustrada, que debe crear un marco legal e institucional de paz y orden que asegure, en definitiva, la continuidad del sistema.

La democracia como «el gobierno de los mejores»-la definición por excelencia entre los políticos de la época- comprueba lo dicho. Con o sin los tintes darwinistas que supone tal apreciación -puesto que "mejor» implica "superior»-, la democracia así conceptuada es la referencia ideológica más común en la clase política regional (47).

En la década del 20, el político jujeo Benjamín Villafae -a quien venimos citando como vocero de la élite azucarera- difunde en sus obras y discursos -de estilo agudo y polémicoesta teoría sobre la democracia. Villafae es un político de notable repercusión en el ámbito local y nacional. Mientras se desempeña como primer magistrado provincial, sus mensajes de apertura en las Sesiones Legislativas o discursos vertidos en ocasiones especiales -tal como las Asambleas de Gobernadores reunidas gracias a su gestión- $\mathrm{y}$, sobre manera, sus posturas en materia de política económica, merecen el apoyo de miembros destacados de la élite nacional, como Alejandro

(47) «Si el temor se fundara en el hábito de la unanimidad -expresa el senador santiagueño Pedro Olaechea y Alcorta al disentir con Joaquín V. González sobre el papel de las minorías- no habrá porque preocuparse de ello, desde que, esa minoría, llenara su rol, controlando la mayoría, y si en el ejercicio de ese control llegara hasta dominar la mayoría por los prestigios del talento, la ilustración y la elocuencia, sería ella la llamada a gobernar desde que, en la democracia, su ideal consiste en que se haga efectivo el gobierno de todos por los mejores de todos; entendido ésto (...) no por la superioridad de razas, desde que nuestra Constitución ha abolido los fueros de nobleza y nuestro régimen político es eminentemente igualitario, sino dentro de las únicas aristocracias compatibles con la índole igualitaria de la democracia: las del talento y de la nobleza y elevación de sentimientos, o, en otros términos, las del cerebro y corazón". Diario de Sesiones de la Cámara de Senadores de la Nación, Año 1911, t. II, pág. 329.

R. I., 1996, n.o 206 
Bunge, Carlos Saavedra Lamas o Matas Sánchez Sorondo. Asimismo, el periodismo local como el de la Capital y otras ciudades importantes lo entrevista y difunde aspectos de su gestión política. Sus ideas y obras de gobierno generan juicios extremos: elogios y calurosas felicitaciones de una parte, censura y crítica feroz de otra.

Si bien afirma en 1922 que es indispensable que se ejerza el derecho al voto para que de la «lucha» se produzca la «selección" y se realice "el ideal democrático", es decir, "el gobierno de los mejores» (48), el correr de los años va desnudando el contenido antidemocrático o autoritario de estas afirmaciones. En su libro «El irigoyenismo. No es un partido político. Es una enfermedad nacional y un peligro público», publicado en 1927, escribe que el dogma de la igualdad humana se malinterpreta, pues se confunde la igualdad ante la ley con la de aspirar a cargos públicos; ello deriva en la demagogía o "chusmocracia», el gobierno de los inferiores (49). Hacia el 30, durante una conferencia pronunciada en Tucumán, reafirma tal concepción:

«Pero es ir contra las leyes naturales, contra la razón y el buen sentido, es minar la civilización por su base, pretender que cualquier ciudadano pueda ocupar la silla del sabio o del estadista, sin inteligencia ni estudio, como si cualquier ciudadano pudiera tomar la dirección del timón de la nave o calcular la fecha del regreso del cometa que cruza la noche y se pierde en lo desconocido» (50).

Desmentir este concepto -el de la igualdad humana- que subvierte el'orden social, no es una mera preocupación filosófica centrada en disentir con Rousseau, sino que se erige en un recurso ineludible para fundamentar su oposición al ejercicio universal de los derechos políticos. En nuestro país, una realidad que inaugura para los varones la Ley Sáenz Peña, vivida

(48) Benjamín VIllafaE: Yrigoyen, último dictador, Buenos Aires, Moro, Tello y Cía., 1922, pág. 58.

(49) Benjamín VillafaE: El irigoyenismo. No es un partido político, es una enfermedad nacional y un peligro público. Contestación del Gobernador de Jujuy a sus detractores, Jujuy, Talleres Gráficos del Estado, 1927, págs. 55-56.

(50) La Industria Azucarera, Año XXXVI, n.o 445, Buenos Aires, noviembre de 1930, pág. 772 . 
como una afrenta por quienes plantean las relaciones sociales dentro de un esquema dualista: de un lado, los hombres ilustres, moralmente sanos e inteligentes, los elegidos de la naturaleza, a los cuales les corresponde la función de dirigir la sociedad; de otro, la multitud, cuyo deber reside en trabajar y dejarse gobernar por «los que piensan» (51).

Ernesto Padilla, como político-azucarero, nos puede proporcionar otro ejemplo de este pensamiento. Su formación dentro del catolicismo social lo inclina a aceptar el concepto de la "armonía de clases» y de la "justicia distributiva», lo cual lo dispone positivamente frente a la ola de reformismo que alcanza a la dirigencia argentina, en especial respecto de la reforma electoral. Pero aún así tiene sus reparos. El estado social argentino, piensa, no está preparado para el ejercicio de la virtud ciudadana, se debe dignificar al pueblo por medio de la educación y de la espiritualidad cristiana.

«La Ley electoral no puede ser un programa sino como un medio -pronuncia en 1911 durante una conferencia-. Es un error banal agitarlo como un pendón. (...) Una buena ley electoral, sin hombres de corazón e ideales es inútil; como para espíritus bien inspirados hasta la más débil armazón legislativa. (...) El pueblo no necesita adulones, sino educadores con la palabra y el ejemplo» (52).

En resumidas cuentas, la participación popular a que abre paso la nueva ley no debe corromper las reglas del «buen gobierno", la ignorancia y las miserias del pueblo no pueden

(51) Nada más significativo que la valoración hecha por Villafae del ascenso del radicalismo al gobierno. Con Yrigoyen, «el llamado régimen (...) fue reemplazado por otro (...), más subalterno, más raquítico y más detestable. Un círculo de hombres de salón (...) bien educados y cultos, resultó reemplazado en el poder por otro círculo, sin educación intelectual, dando (...) la impresión de que los caballeros de la sala, habían sido desplazados por lo pẹor de la servidumbre (...). Parecía que la cocina había sido volcada sobre la sala y los malos criados señoreaban el país (...)». Benjamín VillafaE: Hora Obscura, Buenos Aires, 1935, pág. 16.

(52) Citado por Guillermo Furlong: Ernesto Padilla. Su vida. Su obra, 2. ${ }^{a}$ parte, Universidad Nacional de Tucumán, Fac. de Filosofía y Letras, 1959, pág. 254 y pág. 255.

R. I., 1996, n. 206 
tomar el lugar de la ilustración y la hombría de bien de los que tienen que gobernar.

Estas posturas están en relación con la evolución de las ideas nacionalistas en la Argentina, que hacia la década del 20 comienzan a recibir la influencia de autores franceses como Charles Maurras, Ernest Renán, Hipólito Taine y Gustave Le Bon; entre otros (53). Particularmente este último es muy citado en los escritos del político jujeo. "Los trabajos de Gustave Le Bon -explica David Rock- fueron publicados a lo largo de varias décadas en ediciones argentinas y españolas y se transformaron también en fuerte influencia de los nacionalistas» (54).

Para Le Bon -escribe Emilio de Ipola- «la sociedad es, en todas y cada una de sus manifestaciones, un sujeto sospechoso. Su convicción más constante es que allí donde un grupo tiende a formarse es mejor que, en las cercanías, haya un sólido destacamento de gendarmes para vigilarlos. Teme a lo social -desde la muchedumbre espontánea y efímera hasta el grupo organizado- porque está convencido de su intrínseca perversidad. Perversidad que hunde sus raíces en un inconsciente que el individuo reprime y que la colectividad desata y potencia». En su valoración negativa de la Revolución Francesa «no siente añoranza alguna por los lazos comunitarios disueltos, sino más bien aversión y miedo retrospectivo hacia

(53) Ernest Renán (1923-1892), escritor, filósofo e historiador francés. Jean Touchard lo menciona, junto a Taine, como fundador del neotradicionalismo que se expandirá luego en el nacionalismo francés. En la Reforma intelectual y moral de Francia (1871), Renán sostiene que la crisis en que se hunde su país se debe a la democracia. "Un país democrático no puede estar bien gobernado, bien administrado, bien dirigido", pues la masa sólo se preocupa de su buen pasar.

Hipólito Taine (1828-1893), considerado el más característico representante de la historiografía positivista, su pensamiento es rigurosamente determinista. Tres fuerzas primordiales -que son el "primer motor", las "causas primeras»- regulan, según este autor, «el movimiento total de toda civilización»: la "raza», el "medio» y el "momento».

Sus ideas políticas demuestran adversión tanto del estatismo como de la democracia plesbicitaria y sostiene que la educación, las élites ilustradas y la asociación para luchar contra la influencia del Estado son los caminos a seguir para lograr un buen gobierno.

(54) David RocK, [26], pág. 36. 
las muchedumbres y agitadores profesionales que destruyeron jerarquías, se burlaron de la autoridad y sumergieron a Francia en un inútil y execrable baño de sangre» (55).

Puede entenderse que la nostalgia de alguno de estos autores por un orden perdido o el pensamiento antisocial -atendiendo al análisis de Ipola- de Gustave Le Bon, haya cautivado a intelectuales y políticos de una Argentina conmovida social y políticamente.

El inquietante panorama nacional refuerza el pensamiento nacionalista que se hace eco, asimismo, de la experiencia europea. Allí la Primera Guerra Mundial hace tambalear la confianza en la idea de la humanidad marchando hacia un "progreso indefinido"; mientras que la Revolución Rusa provoca una reacción de los sectores dominantes, los que buscan retener la seguridad amenazada a través de regímenes políticos más fuertes y restrictivos que en las entonces cuestionadas democracias parlamentarias. Se trata, en el examen de Charles Maier citado por Portantiero (56) de una operación profunda de reestructuración de la hegemonía burguesa. La década del 20 da a luz un nuevo sistema político de transacción de los intereses sociales. Las viejas instituciones demoliberales son ya incapaces de mediar en los conflictos. La presencia activa de las clases subalternas en los grandes partidos de masas, obliga a la burguesía a buscar otras formas de articulación fuera del parlamento, que había sido el centro en que ésta elaboraba su unidad política como clase. Las nuevas circunstancias determinan la búsqueda de otras formas de cohesión. «Maier llama al nuevo modelo institucional, al sistema político emergente en esa década de estabilización burguesa, como 'corporativo'» (57).

Aquí «muchos llegaron a la convicción de que peligraba el orden institucional, y achacaron a la Ley Saínz Peña la responsabilidad de los descalabros, acusando a Yrigoyen de débil y de demagogo porque no había extremado aún más la represión para imponer el debido respeto a la autoridad pública $\mathrm{y}$, para-

(55) Emilio DE IPOLA: "La democracia en el amanecer de la sociología», en Sociedad, 1, Universidad de Buenos Aires, octubre de 1992, pág. 105.

(56) Juan Carlos Portantiero: La producción de un orden, Buenos Aires, Nueva Visión, 1988.

(57) İdem., pág. 25. 
lelamente, sujetar a la obediencia a los díscolos sufragistas que -se decía- eran incapaces de asumir la responsabilidad emergente de la libertad del voto" (58).

Se extiende, entonces, la prédica sobre la necesidad de un sistema de gobierno que compatibilice orden, jerarquía y democracia. La aparición en 1919 de la Liga Patriótica demuestra -además de los sentimientos xenófobos de la élite- la intención de imponer esta "fórmula" por medios violentos (59). La vertiente del tradicionalismo católico contribuye singularmente a la difusión de este ideario político y a través de sus propias instituciones laicales, cursos y órganos de concientización, como la revista Criterio -fundada en 1928-, forma a sus cuadros dentro de una concepción autoritaria de poder (60).

Las influencias externas del ya citado Charles Maurras, Primo de Rivera, Ramiro de Maeztu (61), el fascismo italiano tienen su peso en las ideas de quienes se cuentan en las filas de este nacionalismo elitista. Un pensamiento cuya vena antiyri-

(58) A. J. Pérez Amuchastegui: «El hombre», en Crónica Argentina, t. V, Buenos Aires, Cdex, 1972, Páginas Amarillas 5-CX.

(59) «La reacción nacionalista se dio en amplios sectores del espectro político argentino, en especial fuerzas armadas, terratenientes e intelectuales vinculados a las clases altas nativas (...). Una parte importane de la élite modernizadora fue abandonando sus convicciones liberales y apoyó a diversas formas de autoritarismo (...). La primera expresión importante de la reacción nacionalista fue la formación de grupos de ataque y defensa durante la Semana Trágica, en enero de 1919. (...) en la revolución de 1930, estos elementos llegaron al poder, aunque todavía mezclados con muchos componentes liberal-conservadores, sector que sólo veía la necesidad de una corrección temporaria a los excesos de la segunda presidencia de Yrigoyen». DI TELLA, Torcuato: Sociología de los procesos políticos, Buenos Aires, Editorial Universitaria de Buenos Aires, 1988, pág. 360.

(60) Cfr. María Ester RAPALO: "La Iglesia Católica Argentina y el autoritarismo político: la revista Criterio, 1928-1931 ", en Anuario del IEHS, V, Tandil, 1990.

(61) José Antonio Primo de Rivera (1903-1936), fundador del "falangismo» (1933), movimiento político nacionalista, cuyo nombre evoca las falanges o cuerpos de infantería de los antiguos ejércitos griegos. Unido a las Juntas de Ofensiva Nacional Sindicalista (JONS) participa en los alzamientos contra la República. Muere fusilado por los republicanos en Alicante, siendo Francisco Franco su sucesor como líder natural de aquel movimiento.

Ramiro de Maeztu (1874-1930), periodista, ensayista y diplomático español, figura representativa de la Generación del 98 e inspirador del pensamiento integrista español. 
goyenista lo hace partícipe de la confabulación contra el presidente radical para derrocarlo, apoyado por sectores militares. Ya Leopoldo Lugones había preanunciado en 1923 la «hora de la espada»; el golpe de estado de 1930 es su concreción.

Los voceros políticos de los intereses azucareros justificanantes y después de septiembre de 1930, el uso de la fuerza para derrocar a Yrigoyen y de hecho las más relevantes figuras de la "Concordancia» que gobiernan el país entre 1932 y 1943, surgen de las élites de Salta, Jujuy y Tucumán.

Juan B. Terán, fundador de la Universidad Nacional de Tucumán, presidente del Consejo Nacional de Educación entre 1930 y 1932, escribe:

«La Revolución de septiembre que puso a tal régimen (el de la subordinación de la enseñanza a fines facciosos y electorales) justifica su recurso a las armas, entre otras razones, porque éste se había abrogado las leyes constitucionales (...). Tales ideas coinciden con las que constituían y constituyen mi convicción (...)» (62).

El mismo Villafae -senador nacional en el período 19321941-, con su teoría de la verdadera democracia como "gobierno de los mejores» o "dictadura de los hombres superiores", se arriesga a valorar sobre la existencia o no de crimen en los asesinatos políticos según quien fuera el destinatario, la persona de un Lincoln o de un Yrigoyen.

Si la Industria Azucarera recibe el nuevo gobierno como al "Salvador de la Patria en uno de los trances de mayor significación histórica» (63), es porque la élite confía en la perspectiva de una "saludable reacción" en la política económica; y aunque en realidad las medidas del nuevo equipo económico no trastocan toda la organización de la economía interna ni tampoco equilibran la relación nación-provincias, se debe tener en cuenta que «la política económica implementada durante el período de los Gobiernos de la Concordancia respondió a la necesidad de subsistencia del sistema conservador nacional» (64).

(62) Juan B. TERÁN: Obras Completas, t. X, «Espiritualizar nuestra escuela», UNT, 1980, págs. 13-14.

(63) Benjamín VillafaE: Degenerados, [25], pág. 147.

(64) La Industria Azucarera, Año XXXVI, n.o 448, Bs As, febrero de 1931, pág. 120.

R. I., 1996, n. ${ }^{\circ} 206$ 
El proyecto político de la élite azucarera no es otro que el del «nacionalismo de derecha» o «aristocrático» (65), que proclama la vigencia de «un gobierno eficaz, honorable y de orden", que mantenga "al pueblo dentro del orden y respeto a la autoridad", y donde el Congreso y los partidos políticos no se dediquen a "servir a las clientelas electorales», organizándose en cambio la "gran falange de la verdadera democracia", en oposición a la "orgía demagógica» a que había dado lugar el sufragio libre (66), según los conceptos del azucarero salteo Robustiano Patrín Costas, presidente del Partido Democráta Nacional entre 1931 a 1935, de la Concordancia entre 1930 y 1943 y Presidente Provisional del Senado de la Nación durante el mismo lapso.

Se hace evidente, pues, que el pensamiento social -elitista y retrógrado- de la burguesía azucarera está integrado con las ideas políticas de un sistema, cuya legitimidad será cuestionada por el avance de los sectores populares, encauzados por el radicalismo yrigoyenista.

La concepción de un orden social que preservara los privilegios de la élite, junto a la de un sistema político que garantizase el "gobierno de los mejores», explican su oposición al gobierno surgido en las urnas en 1916. Y la identidad de sus proyectos políticos con el de los gobiernos de la «Década Infame»; más aún, la contribución de la élite azucarera regional a la conformación de una ideología cuyos resabios aún hoy están presentes en el pensamiento de nuestras clases dirigentes.

El proceso de cambios económicos, sociales y político que deviene en la Argentina desde su integración al mercado internacional se expresa durante los años aquí considerados en el avance de una legislación social en favor de las clases trabajadoras y en la Ley del Voto, que marca el ocaso del régimen conservador.

Frente a estos hechos, la burguesía va a cerrar filas en defensa de sus intereses de clase, propiciando una restricción

(65) Amalia A. Louro DE ORTIZ: El Grupo Pinedo-Prebisch y el Neoconservadorismo renovador, Buenos Aires, Grupo Editorial Latinoamericano, 1992, pág. 63.

(66) Cfr. Daniel CAMPI: «El nacionalismo hispanoamericano de Ral Scalabrini Ortiz», en Actas del Congreso Internacional de Historia de América, Córdoba, 1987. 
de las libertades públicas y un freno a las conquistas laborales para controlar a las masas rurales y urbanas y, en general, a cuanta expresión se presentara de subvertir el orden «natural» de la sociedad, jerárquicamente organizada y conducida solamente por quienes estaran destinados a ello.

Justifica su resistencia patronal a las leyes obreras por la subida en los costos de produccción -se argumenta- que éstas acarrean, en perjuicio de la competitividad de la industria azucarera nativa. Por considerarlas violatorias de la libertad contractual entre empleadores y obreros consagrada en la Constitución Nacional; y por el fin político que persiguen, al sancionarse para atender los reclamos de la población consumidora que, concentrada en el Litoral, constituye el mayor caudal electoral de los partidos que las propician.

El elitismo social de los industriales azucareros se integra perfectamente con los planteos de las corrientes nacionalistas que obtienen gran repercusión en las clases dirigentes argentinas, en especial durante la década del 20. Comparte con ellas la aversión al gobierno surgido de las urnas en 1916, sobre todo porque éste iba a traerle acarreada la pérdida del usufructo monopólico del poder político en el Norte, que ahora deba compartir.

Las discrepancias en materia de política económica constituyen otro punto importante en el análisis de su antiyrigoyenismo, aquí sólo mencionado, pero que ha sido objeto de avance en un trabajo anterior (67).

El estudio del pensamiento social de la élite azucarera puede contribuir a la explicación de los componentes ideológicos que sustentan los comportamientos de clase del grupo social de mayor peso en la región. Como asimismo al análisis de las claves interpretativas del pensamiento político y social de la Región, a la luz de las problemáticas planteadas por nuestras clases dirigentes hoy (68).

(67) Carlos Luque Colombres: Patrón Costas en la Historia, Córdoba, 1991, págs. 213, 217 y 220 .

(68) Cfr. María Silvia Fleitas: "El pensamiento económico y social de la élite azucarera del Noroeste Argentino (1912-1930)", Tesis de Licenciatura en Historia, FHCS, Universidad de Jujuy, 1993.

\section{R. I., 1996, n.o 206}


Towards the end of the nineteenth century, an interesting phenomenon in the history of ideas developed in Argentina, focusing on the definition of "national identity", in the context of massive arrival of inmigrants and the social tensions this caused. This study examines the social and economic factors that influenced the positions adopted by the northwestern sugar elite regarding the so-called "social issue». 